\title{
Decentralized Production Circulation and Arrangement in Supply Chain Using Smart Operatives
}

\section{Aruna Dhamija ${ }^{1}$}

${ }^{1}$ Professor, Institute of Business Management, GLA University, Mathura, India. E-mail:aruna.dhamija@gla.ac.in

Article History: Received: 11 January 2021; Accepted: 27 February 2021; Published online: 5 April 2021

\begin{abstract}
Under the assumptions of complete sharing of information between organizational departments and the presence of an independent decision making authority for the entire supply chain, previous supply chain research highlights centrally controlled models. Due to information privacy, most of the facilities in the supply chain are functionally centralized in exercise. Collaboration between these functional units is most important for responding to rapid changes in customer requirements and for resolving conflicts. Intelligent Agent Systems have been shown to be effective in achieving collaboration and effective communication in the environment of distributed decision making. In this paper, intelligent agents are proposed and validated Reducing cost of a decentralized distribution planning process for development for multiple echelons, multiple products and multiple intervals.
\end{abstract}

Keywords: Smart Operatives, Intelligent Agents, Multi Echelon Supplychain, Decentralized Production Distribution.

\section{Introduction}

The supply chain has a direct influence on any business enterprise's success. Effective decision-making in the supply chain has several difficulties [1]. Researchers have proposed different supply chain models and methodologies with the assumption that decisions are taken by an independent authority with respect to the global supply chain goal[2]. Most of the supply chain installations, however, are functionally decentralized[3]. Due to the data privacy of each entity, there is incomplete information sharing between facilities. Collaboration between these functional units is the most important act in response to rapid changes in customer requirements and conflict resolution [4 -6] Intelligent Agent Systems (IAS) have been shown to be effective in areas refers to an interaction between distributed systems, which include different ideologies. [7]. A intelligent agent is a software application capable of managing its own judgement and acting on either basis of its analysis of its situation to achieve its goals and objectives[8, 9]. An agent must exhibit three important general characteristics: autonomy, adaptation and cooperation. Figure 1 shows an intelligent agent and its environment [10-13]. IAS comprise a number of intelligent agents, every agent endeavor for maximizing its own usefulness while coordinating with added agents for achieving their objectives [14]. IAS is widely applied to concurrent engineering, manufacturing planning [15], scheduling and control, manufacturing enterprise integration and supply chain etc.

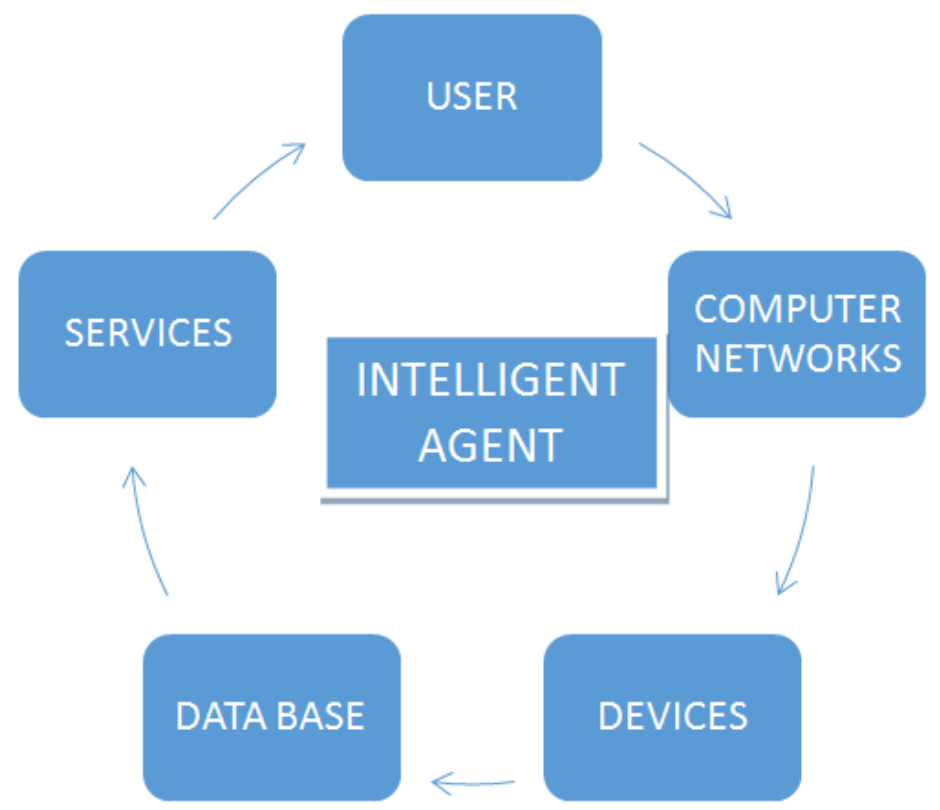

Figure 1. Schematic Network of Intelligent Agent 


\section{Literature Review}

For effective and efficient supply chain decisions, researchers have suggested different models and methodologies, and modelling approaches range from mathematical, game statistics and research analysis to modelling and simulation of systems. Numerous analytical optimization models are designed to reduce costs or improve sustainability. Syarif et al (1) used a spanning tree-based Genetic Algorithm (GA) To explore the alternative of opening services and the specification of the circulation network to meet client needs at the lowest cost. Park[2] suggested a heuristic method to demonstrate the efficacy of an integrated planning approach to output delivery over a decoupled approach in a circulation system of two-stage. Kumanan et al. [3] contrasted GA and Particle Swarm Optimization efficiency for a three-stage distribution network model with a view to minimizing total cost. Performance measures were often seen as a complement to cost analysis like delivery reliability, delivery lead time, versatility, quality and responsiveness. Chan et al.[4] In order to solve the supply chain distribution network problem As performance measures, with operating costs, distribution periods and utilization ratio, analytical hierarchy processes were merged with GA. Altiparmak et al.[5] supplied Nonlinear mixed integer programming and GA (Genetic Algorithm) with cost, availability fill rate and focus usage ratio, for supply chain design. A multifaceted optimization algorithm to plan the distribution of bi-criteria was proposed by Prasanna Venkatesan and Kumanan [6] in the supply chain.

Analytical optimization models have been shown to be effective in a number of cases, although they are still too simple to be used functionally for a complex supply chain encompassing uncertain and diverse behavior patterns. On the other hand, simulation models can capture realistic characteristics of the supply chain supported that the designer can integrate these attributes throughout the simulation model efficiently. [7]. Kumanan et al. [8] proposed a GA and a spreadsheet based simulation to model and analyze supply chain distribution problem under demand fluctuation. A review of the work on supply chain simulation is presented by Terzi and Cavalieri (9). Lim et al. [10] developed a simulation model to analyze the production-distribution plan for a time variant customer demand [16]. Centralized models are emphasized in the past research with the assumption of complete information sharing among functional units [17]. In practice most of the facilities in supply chain are functionally decentralized due to information privacy [18 - 20].

Collaborative agents have the benefits of maintaining collaborative decision-making and resolving conflicts in a variety of business activities or categories. In many fields of research, which include industrial production, engineering and computer applications, a very appropriate research of the acceptance of agents has been documented as well as illustrated. A review of multi agent supply-chain has been reported by Tian and Tianfield [21-25, 37-38]. Utilizing the agents in collaboration the decentralized production distribution planning was proposed by Jung and Jeong [12]. A constraint network along with agent technology to coordinate the supply chain and GA for searching demand ordering quantity is proposed by Liang and Hung [26, 29-31]. In this paper intelligent agents are proposed and validated for a multi echelon, multi product and multiple periods decentralized production distribution planning system with the objective of minimizing the cost $[27,28,32-36]$.

\section{Improvised Formulation of Distribution Network}

A decentralized two-step distribution network is a linear optimization problem with the aim of reducing the total cost as shown in figure 2. Total cost includes cost of production and cost of distribution.

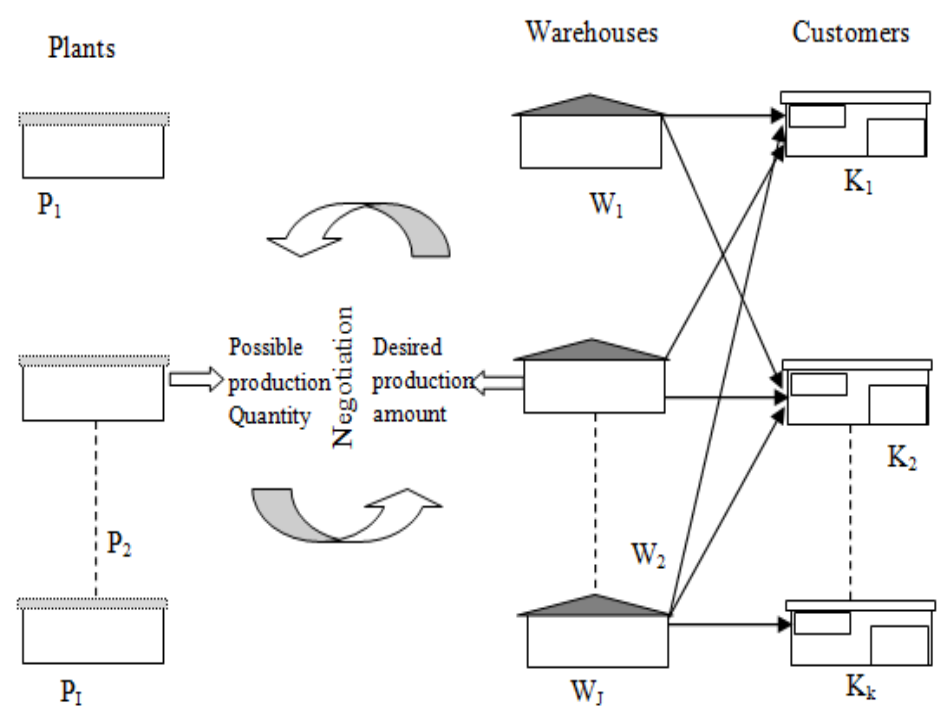

Figure 2. Decentralized Production Distribution Network [37] 


\subsection{Expectations}

- Demand driven distribution network.

- Numbers of plants, warehouses are known.

- Lacking or backorder is not permissible.

- The cost of production unit will not transform with quantity produced.

- The cost of delivery will not transform with the quantity delivered

- Manufacturing plants can produce the same product with equal quality and features.

Indices

No. of plants iє $\{1,2, \ldots \mathrm{A}\}$

No. of warehouses $j \in\{1,2, \ldots \mathrm{B}\}$

No. of clients $k \in\{1,2, \ldots \mathrm{C}\}$

No. of time period $t \in\{1,2, \ldots \mathrm{M}\}$

No. of products $\mathrm{p} \in\{1,2, \ldots \mathrm{Q}\}$

\subsection{Constraints}

$D_{\mathrm{kpt}} \quad$ Request from client " $\mathrm{k}$ " for product " $\mathrm{p}$ " over a period of time " $\mathrm{t}$ "

$\mathrm{F}_{\mathrm{it}} \mathrm{M} \quad$ Max. production capacity of plant "I" during period " $\mathrm{t}$ "

$\mathrm{W}_{\mathrm{jpt}} \quad$ Warehouse inventory handling capacity " $\mathrm{j}$ " for product " $\mathrm{p}$ " during the period of time " $\mathrm{t}$ "

$\mathrm{E}_{\mathrm{it}} \quad$ Whole available inventory capacity for plant " $\mathrm{I}$ " in period " $\mathrm{t}$ "

$\mathrm{Q}_{\mathrm{rpit}} \quad$ Desired production quantity for product " $\mathrm{p}$ " at plant "I" in period " $\mathrm{t}$ "

$\mathrm{U}_{\mathrm{ip}} \quad$ Rate of utilization of production capacity per unit of product "p" in plant " $\mathrm{I}$ "

$\mathrm{U}_{\text {eip }} \quad$ Warehouse utilization rate per unit of product "p" in plant

$\mathrm{C}_{\mathrm{hpjt}} \quad$ Inventory unit holding cost for product "p" at warehouse " $\mathrm{j}$ " during period " $\mathrm{t}$ "

$\mathrm{C}_{\mathrm{dpjijt}} \quad$ Actual cost of transport for product "p" from plant to warehouse " $\mathrm{j}$ " during period " $\mathrm{t}$ "

$\mathrm{C}_{\mathrm{dpjkt}} \quad$ Transportation cost for product " $\mathrm{p}$ " from warehouse; to customer " $\mathrm{k}$ " in period " $\mathrm{t}$ "

$\mathrm{C}_{\text {upkt }} \quad$ Product $\mathrm{p}$ Customer Zone " $\mathrm{k}$ " unfulfilled penalty costs in period " $\mathrm{t}$ "

$\mathrm{C}_{\text {mpit }} \quad$ Unit production cost for product "p" at plant " $\mathrm{I}$ " in period " $\mathrm{t}$ "

$\mathrm{C}_{\text {hpit }} \quad$ Unit inventory holding cost for product "p" at plant "I" in period " $\mathrm{t}$ "

$\mathrm{C}_{\text {upit }}$ System unsatisfied penalty costs for the required quantity from the distribution agent at plant "I" for product " $p$ " in period " $\mathrm{t}$ "

\subsection{Variable Quantity}

$\mathrm{Q}_{\mathrm{pit}} \quad$ Production amount for plant I product $\mathrm{p}$ in period t.

$\mathrm{Q}_{\mathrm{rpit}} \quad$ Production amount needed (desired) for product $\mathrm{p}$ at plant I during period $\mathrm{t}$

Qhpit Product $\mathrm{p}$ inventory in plant i during period $\mathrm{t}$

$\mathrm{Q}_{\mathrm{dpijt}} \quad$ Product quantity transmission from plant $\mathrm{I}$ to warehouse $\mathrm{j}$ during period $\mathrm{t}$

Qhpjt Product $\mathrm{p}$ inventory quantity in warehouse $\mathrm{j}$ in time $\mathrm{t}$

Qdpjkt quantity of transport for the product $\mathrm{p}$ of the warehouse;

Qupkt unaccomplished product $\mathrm{p}$ request quantity at client $\mathrm{k}$ in period $\mathrm{t}$

Qupit unaccomplished amount for product $\mathrm{p}$ at plant $\mathrm{I}$ in time $\mathrm{t}$ against both the requested amount 
Here is a mathematical model for distribution is given below.

$$
\mathrm{F}_{\mathrm{d}}(\mathrm{x})=\sum_{p . j . t} Q_{h p j t} \times C_{d p i j t}+\sum_{p . i . j . t} Q_{d p i j t} \times C_{d p i j t}+\sum_{p . j . k . t} \times C_{d p j k t}+\sum_{p . k . t} Q_{u p k t} \times C_{u p k t}
$$

subject to

$$
\begin{aligned}
& \sum_{p . i . j . t} Q_{d p i j t}=D_{k p t}-Q_{u k p t} \forall k, p, t \\
& \sum_{p, j, t} Q_{h p j t-1}+\sum_{p, i, j, t} Q_{h p j t}=\sum_{p, j, t} Q_{h p j t}+\sum_{p, j, k, t} Q_{d p j k t} \\
& \sum_{p, j, t} Q_{h p j t} \leq \sum_{p . j . t} W_{p j t} \\
& \sum_{p, j, t} Q_{h p j t} \leq \sum_{p . j . t} W_{p j t} \\
& \sum_{p . i, j, t} Q_{d p i j t} \leq \sum_{i . t} F_{i t} \\
& Q_{p i t,} Q_{r p i t}, Q_{d p i j t,} Q_{h p j t} Q_{d p j k t} Q^{\mathrm{e}} 0
\end{aligned}
$$

Equation (1) minimizes the total distribution cost. Constraint (2) represents the restriction on total distribution quantity. Inventory balance is shown in equation (3). Equations (4) (5) and (6) represent the capacity constraint for warehouses and plants. Non-negativity constraints are represented in equation (7).

Mathematical model for production is shown below.

$$
\begin{aligned}
& \mathrm{f}_{\mathrm{m}}(x)=\sum_{p . i . t} Q_{p i t} \times C_{m p i t}+\sum_{p . i . t} Q_{r p i t} \times C_{h p i t}+\sum_{\text {i.p.t }} Q_{u p i t} \times C_{\text {uipt }} \\
& \sum_{p, i, t} Q_{h p i t-1}+\sum_{p, i, t} Q_{p i t}=\sum_{p, i, t} Q_{r p j t}+\sum_{p, i, t} Q_{h p i t}-\sum_{p . i . t} Q_{u p i t}
\end{aligned}
$$

Subject to

$$
\begin{aligned}
& \sum_{p, i, t} Q_{p i t} \leq F_{i t} \\
& \sum_{p, i, t} Q_{h p i t} \leq E_{i t} \\
& Q_{p i t}, Q_{h p i t}, Q_{d p i j t}, Q_{u p i t}, e^{\prime \prime} 0
\end{aligned}
$$

Equation (8) minimizes the total production cost. Constraint (9) represents the inventory balance for plants. Equations (10) and (11) represent the capacity constraint for plants. Non-negativity constraints are represented in equation (12).

\section{Development of Software}

The research framework is being developed on the Matlab platform. Two collaborative agents are considered in the proposed methodology. Distribution Agent (DA) and Production Agent; (PA). Figure 3 illustrates the operating principle of the two collaborative agents. The main purpose of DA is to generate a distribution plan for products from plants to customer areas through the warehouse and to give the PA the required quantity of production. The function of PA is to generate a production plan for the plants to satisfy the customer demands and communicate the feasible production quantity to the DA. Within the suggested solution, the DA begins with a distribution plan that assumes never-ending plant production capability, and then calculates the desired output quantity, which is fed to the PA as input. Figure 4 Schematic flow diagram of work flow of intelligent agents

The PA uses the real constraining details (e.g. plant capacity, unit cost of output, etc.) and the expected production quantity from the DA to create a plan of production. If the PA's produced production plan fails to meet a DA requirement, the PA will communicate the potential production quantity taking into account existing capability of production, and after that the DA will reconstruct the possible plan of distribution considering the PA's potential production quantity. Such iterations of planning carry on unless no planning difference is there between the PA and the DA, meaning that the PA fully meets the required quantity of input from the DA. As far as PA and DA are concerned, cooperation between two agents is required for improving the consistency of the solution and for making procedures work before the conditions for stopping are met. 


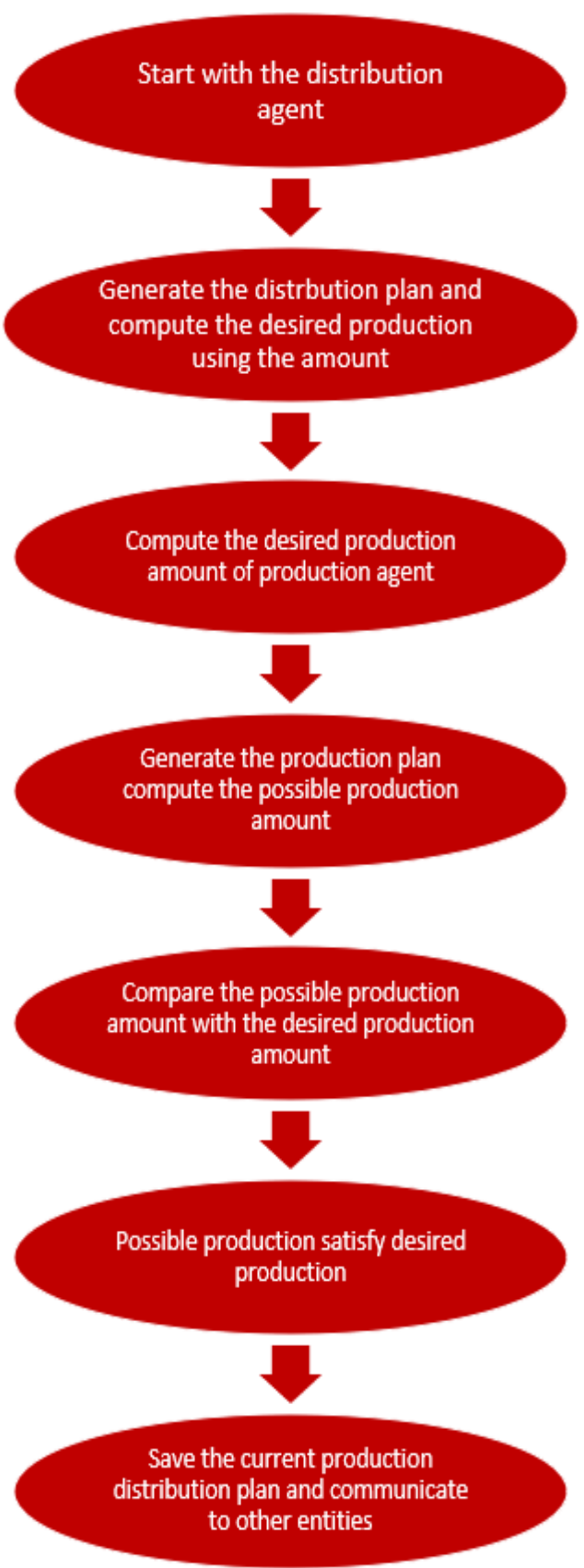

Figure 3. Working of Intelligent Agents

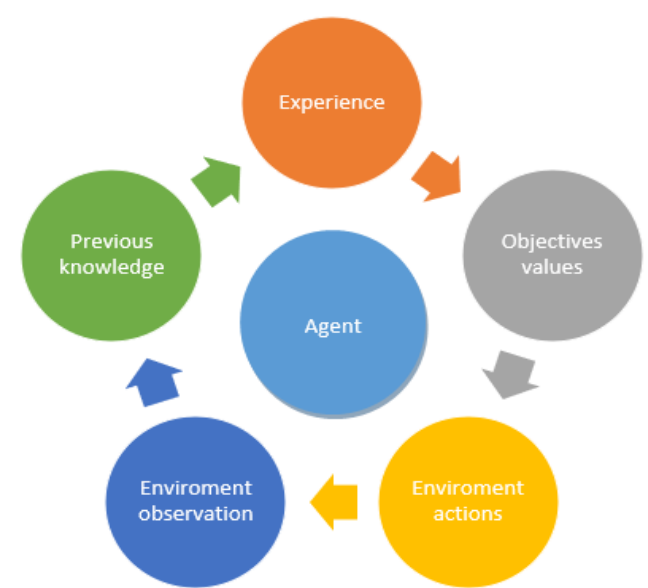

Figure 4. Schematic Flow Diagram of Work Flow of Intelligent Agents 


\section{Numerical and Probabilistic Illustration for A Decentralized Supply Chain}

A plan for the distribution of the minimum cost of production for a decentralized supply chain network is to be developed. A limited supply chain is believed to have a single colour, one warehouse and one customer. Three separate items (A, B, and C) may be ordered by each user for six periods of time. Simulated consumer demand data is shown in Table 1 for three different items. Production cost, inventory handling cost, penalty cost and the distribution costs are shown in table 2.

Table 1. Demand of product for Six Time Period

\begin{tabular}{lccc}
\hline Period & \multicolumn{3}{c}{ Products } \\
& A & B & C \\
\hline 1 & 300 & 400 & 500 \\
2 & 150 & 430 & 100 \\
3 & 500 & 340 & 350 \\
4 & 200 & 220 & 250 \\
5 & 700 & 450 & 350 \\
6 & 30 & 120 & 600 \\
\hline
\end{tabular}

In comparison to the requested amount, both PA and DA require penalty costs for amounts that are unfulfilled. Table 3 shows the capacity-related data. The utilization rates at the plant and warehouse shall be presumed as 1 .

Table 2. Illustrative Example on Cost Details for Per Unit

\begin{tabular}{llll}
\hline \multicolumn{1}{c}{ Cost per unit per period (INR) } & \multicolumn{3}{c}{ Product } \\
& $\mathbf{X}$ & $\mathbf{Y}$ & $\mathbf{Z}$ \\
\hline Production cost at plant & 20 & 15 & 20 \\
Inventory holding cost at plant & 4 & 4 & 4 \\
Penalty cost at plant & 15 & 18 & 20 \\
Distribution cost from & 12 & 14 & 14 \\
& & & \\
[][][]][]][]][]]]]]]] & & & \\
$7 / 7465$ plant to warehouse & 1 & 2 & 1 \\
Inventory holding cost at warehouse & 28 & 20 & 30 \\
Distribution cost from warehouse to customer & 25 & 32 & 34 \\
Penalty cost at warehouse & & & \\
\hline
\end{tabular}

Table 3. Illustrative Example on Plant and Capacity of Warehouse

\begin{tabular}{ll}
\hline \multicolumn{1}{c}{ Warehouse and Plant Capacity } & Units \\
\hline Inventory Holding capacity for pant & 300 \\
Production capacity for plant & 500 \\
Inventory holding capacity for warehouse & 400 \\
Min. inventory in a plant & 40 \\
Min. inventory in a warehouse & 40 \\
\hline
\end{tabular}

A production-distribution plan starting with the DA begins with the planned decentralized preparation, and computational iteration is performed until the termination situation is fulfilled. The terminating condition may be said to be satisfied if the PA meets the entire necessary (desired) output quantity from the DA. At each stage a production-distribution plan is generated till the stage when the minimum cost is reached and the corresponding plan gives the optimal plan for each period. In this example, the production distribution plan is obtained after seventh iteration. The planning results obtained during 7th iteration are shown in the tables 4 and table 5 for period 1 and 6.

Table 4. Plan of Production Distribution for Period 1

\begin{tabular}{|c|c|c|c|}
\hline \multirow[t]{2}{*}{ Decision variables } & \multicolumn{3}{|c|}{ Products } \\
\hline & A & B & C \\
\hline Qhpit & 30 & 30 & 30 \\
\hline$Q_{\text {dpijt }}$ & 150 & 30 & 30 \\
\hline $\mathrm{Q}_{\mathrm{dpjkt}}$ & 160 & 0 & 0 \\
\hline $\mathrm{Q}_{\text {upit }}$ & 80 & 400 & 500 \\
\hline $\mathrm{Q}_{\text {pit }}$ & 200 & 50 & 50 \\
\hline $\mathrm{Q}_{\text {hpit }}$ & 30 & 30 & 30 \\
\hline Qupkt & 0 & 0 & 0 \\
\hline
\end{tabular}


Table 5. Plan of Production Distribution for Period 6

\begin{tabular}{llll}
\hline Decision variable quantity & \multicolumn{3}{c}{ Products } \\
& A & B & C \\
\hline Qhpit $_{\text {Q }}$ & 30 & 30 & 30 \\
Q $_{\text {dpijt }}$ & 30 & 150 & 75 \\
Qdpjkt $_{\text {Qupit }}$ & 30 & 150 & 65 \\
Q $_{\text {pit }}$ & 0 & 400 & 746 \\
Qhpjt $_{\text {Qupkt }}$ & 30 & 150 & 150 \\
\hline
\end{tabular}

Table 6. Computational Outcomes by Projected Method

\begin{tabular}{llll}
\hline Repetitions & Distribution cost $\left(\mathbf{D}_{\mathbf{C}}\right)$ & Production Cost $\left(\mathbf{P}_{\mathbf{C}}\right)$ & Total cost $\left(\mathbf{T}_{\mathbf{C}}\right)$ \\
\hline 1 & 155200 & 61660 & 234350 \\
2 & 164200 & 54069 & 215690 \\
3 & 166350 & 42580 & 188000 \\
4 & 167270 & 30000 & 185450 \\
5 & 148650 & 20080 & 172150 \\
6 & 160110 & 17649 & 176329 \\
7 & 169520 & 16000 & 175230 \\
\hline
\end{tabular}

Table 6 displays the overall costs incurred during the iterations. As iteration continues, the cumulative cost decreases steadily. With iterations, the distribution cost increases as the output cost decreases. That's because of the DC-PC negotiation process. DC begins with the presumption that the unit's output potential is never-ending since the DC primarily obtains the perfect plan of distribution without taking into account the unit of production.

After the first planning iteration, DC will regenerate the delivery plan with potential output input from the PC. The desired production volume for the PC derived from DC can be estimated by adding the transport volumes between the plant and the warehouse. The agent based approach is much realistic compared to the centralized modelling approach that assumes ideal communication among entities.

\section{Conclusions}

Throughout this project, the two-stage decentralized distribution network of production is modelled upon as a linear problem of optimization in order to reduce the entire expense. Intelligent agents are recommended, by collaboration and negotiation, to achieve the minimum cost package. Using simulated data, the performance of the proposed method is checked. The next task is to integrate a few more stock, purchase and demand forecasting agents and to introduce more agent features.

\section{References}

7. Syarif, A., Yun, Y., \& Gen, M. (2002). Study on multi stage logistic chain network: a spanning tree based genetic algorithm approach. Computers and Industrial Engineering, 43(1-2), 299-314.

8. Park, Y.B. (2005). An integrated approach for production and distribution planning in supply chain management. International Journal of Production Research, 43(6), 1205-1224.

9. Goyal, M. (2018). Shape, size and phonon scattering effect on the thermal conductivity of nanostructures. Pramana, 91(6), 87.

10. Goyal, M., \& Gupta, B.R.K. (2019). Study of shape, size and temperature-dependent elastic properties of nanomaterials. Modern Physics Letters B, 33(26), 1950310.

11. Kumanan, S., Prasanna Venkatesan, S., \& Prasanna Kumar, J. (2007). Optimization of supply chain logistics network using random search techniques. International Journal of Logistics Systems and Management, 3(2), 252-266.

12. Chan, F.T.S., \& Chung, S.H. (2004). Multicriteria genetic optimization for distribution network problems. International Journal of Advanced Manufacturing Technology, 24(7-8), 517-532.

13. Mausam, K., Sharma, K., Bharadwaj, G., \& Singh, R.P. (2019). Multi-objective optimization design of diesinking electric discharge machine (EDM) machining parameter for CNT-reinforced carbon fibre nanocomposite using grey relational analysis. Journal of the Brazilian Society of Mechanical Sciences and Engineering, 41(8), 348.

14. Shukla, M.K., \& Sharma, K. (2019). Improvement in mechanical and thermal properties of epoxy hybrid composites by functionalized graphene and carbon-nanotubes. Materials Research Express, 6(12), 125323.

15. Kumar, K., Sharma, K., Verma, S., \& Upadhyay, N. (2019). Experimental Investigation of GrapheneParaffin Wax Nanocomposites for Thermal Energy Storage. Materials Today: Proceedings, 18, 5158-5163. 
16. Goyal, M., \& Gupta, B.R.K. (2019). Analysis of shape, size and structure dependent thermodynamic properties of nanowires. High Temperatures--High Pressures, 48(5/6), 481-495.

17. Goyal, M., \& Singh, M. (2020). Size and shape dependence of optical properties of nanostructures. Applied Physics A, 126(3), 1-8.

18. Altiparmak, F., Gen, M., Lin, L., \& Paksoy, T. (2006). A genetic algorithm approach for multi-objective optimization of supply chain networks. Computers \& Industrial Engineering, 51(1), 197-216.

19. Prasanna Venkatesan, S., \& Kumanan, S. (2008). A multi objective particle swarm optimization for distribution planning in supply chain network. In Proceedings of 18th International Conference on Flexible Automation and Intelligent Manufacturing (FAIM), Skövde, Sweden, 574-581.

20. Singh, P.K., \& Sharma, K. (2018). Molecular Dynamics Simulation of Glass Transition Behaviour of Polymer based Nanocomposites. Journal of Scientific \& Industrial Research, 77(10), 592-595.

21. Kumar, A., Sharma, K., \& Dixit, A.R. (2020). Carbon nanotube-and graphene-reinforced multiphase polymeric composites: review on their properties and applications. Journal of Materials Science, 1-43.

22. Shukla, M.K., \& Sharma, K. (2019). Effect of carbon nanofillers on the mechanical and interfacial properties of epoxy based nanocomposites: A review. Polymer Science, Series A, 61(4), 439-460.

23. Kumar, A., Sharma, K., \& Dixit, A.R. (2020). A review on the mechanical and thermal properties of graphene and graphene-based polymer nanocomposites: understanding of modelling and MD simulation. Molecular Simulation, 46(2), 136-154.

24. Akanle, O.M., \& Zhang, D.Z. (2008). Agent based model for optimizing supply chain configurations. International Journal of Production Economics, 115(2), 444-460.

25. Kumanan, S., Prasanna Venkatesan, S., Kumar, K., \& Prasanna Kumar, J. (2006). Performance analysis of supply chain network using a genetic algorithm and simulation. International Journal of Agile Systems and Management, 1(4), 450-462.

26. Terzi, S., \& Cavalieri, S. (2004). Simulation in the supply chain context: a survey. Computers in industry, 53(1), 3-16.

27. Lim, S.J., Jeong, S.J., Kim, K.S., \& Park, M.W. (2005). A simulation approach for production-distribution planning with consideration given to replenishment policies. The International Journal of Advanced Manufacturing Technology, 27(56), 593-603.

28. Tian, J., \& Tianfield, H. (2006). Literature review upon multi-agent supply chain management. In International Conference on Machine Learning and Cybernetics, 89-94.

29. Sharma, K., Kaushalyayan, K.S., \& Shukla, M. (2015). Pull-out simulations of interfacial properties of amine functionalized multi-walled carbon nanotube epoxy composites. Computational Materials Science, 99, 232-241.

30. Yadav, A., Kumar, A., Singh, P.K., \& Sharma, K. (2018). Glass transition temperature of functionalized graphene epoxy composites using molecular dynamics simulation. Integrated Ferroelectrics, 186(1), 106-114.

31. Singh, P.K., Sharma, K., Kumar, A., \& Shukla, M. (2017). Effects of functionalization on the mechanical properties of multiwalled carbon nanotubes: A molecular dynamics approach. Journal of Composite Materials, 51(5), 671-680.

32. Singh, P.K., \& Sharma, K. (2018). Mechanical and Viscoelastic Properties of In-situ Amine Functionalized Multiple Layer Grpahene/epoxy Nanocomposites. Current Nanoscience, 14(3), 252-262.

33. Jung, H., \& Jeong, B. (2005). Decentralized production-distribution planning system using collaborative agents in supply chain network. International Journal of Advanced Manufacturing Technology, 25(1-2), 167-173.

34. Liang, W.Y., \& Huang, C.C. (2006). Agent based demand forecast in multi echelon supply chain. Decision support systems, 42(1), 390-407.

35. Tarkar, P., Dhamija, S., \& Singh, P. (2019). A Mediation Effect of Job Satisfaction and Affective Commitment in Relationship between Passion and Work Intentions after Retirement. Vision, 23(2), 197-207.

36. Tarkar, P., \& Dhamija, S. (2020). The influence of perceived social support on quality of life and intention towards work after retirement. International Journal of Scientific and Technology Research, 9(2), 35203523.

37. Agrawal, A., \& Dhamija, S. (2020). Sway of demography-based factors over the decision-making procedure pertaining to household investors. International Journal on Emerging Technologies, 11(2), 92-98.

38. Khan, W., Akhtar, A., Ansari, S.A., \& Dhamija, A. (2020). Enablers of halal food purchase among Muslim consumers in an emerging economy: an interpretive structural modeling approach. British Food Journal, $122(7), 2273-2287$.

39. Dhamija, A. (2020). The changing paradigms and evolving dynamics of faith-based tourism in India. International Journal of Scientific and Technology Research, 9(2), 2347-2352.

40. Kwon, H.Y. (2019). Research on the Actual Condition of Youth Happiness and Related Variables. Asiapacific Journal of Convergent Research Interchange, 5(3), 179-188. 
41. Park, J.H. (2019). The Effects of Mobile Application on Acceptance, Learning Flow, Knowledge, and Study Crafting for Nursing Students. Asia-pacific Journal of Convergent Research Interchange, 5(3), 189-199.

42. Park, J.H. (2019). The Effects of Action Learning on Problem-solving Process, Team Efficacy, and Team Outcome of Nursing Students. Asia-pacific Journal of Convergent Research Interchange, 5(3), 201-209.

43. Venkatesan, S.P., Kumanan, S., Dutta, P., \& Kumar, S. (2008). Decentralized Production Distribution Planning in Supply Chain Using Intelligent Agents. Proceedings of SCMIS 2008, Tiruchirappalli, India, 120-128. 